\title{
A message from the buried past: \\ Deciphering the location of ancient settlements
}

\author{
Hadar Elyashiv
}

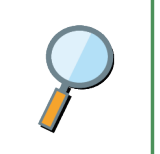

Follow this sign to see the observations, evidence, and interpretation of the data from Haifa Bay.

\section{How can we know what a coastal} environment looked like $\mathbf{4 0 0 0}$ years ago?

In a world with no cars or public transportation, going to the sea to fish or to collect food along the coast, even 1 kilometer or 1 mile can be too far. So why are settlements from 4000 years ago now located between 2-5 $\mathrm{km}$ (1-3 miles) away from the coastline? This question has troubled archaeologists who studied the coastal area now called Haifa Bay in Israel. It is especially puzzling as we know that fishermen would choose to live close to the water, where they can leave their boats rather than carry them.

Did people 4000 years ago have special technology, or was the coastline in a different position than it is today? How can we know what a coastal environment looked like 4000 years ago? Knowing the answer could help us understand how people lived in the past and perhaps tell us about possible future changes to the coastline.

To reconstruct the past environment, a geologist's work resembles the work of a detective reconstructing a crime scene. It begins with observing and collecting evidence such as field observations, sediments, and fossils samples. Once samples are analyzed, the geologist must interpret these natural clues - how did they get there, where did they come from, and how old are they?

\section{How can we find the past in the present?}

A first step towards environmental reconstruction is to follow the principle "the present is the key to the past". This principle suggests that processes we see today also happened in past times. In order to understand how a coastal environment looked like thousands of years ago, we first need to observe how the coastal environment looks and functions today.

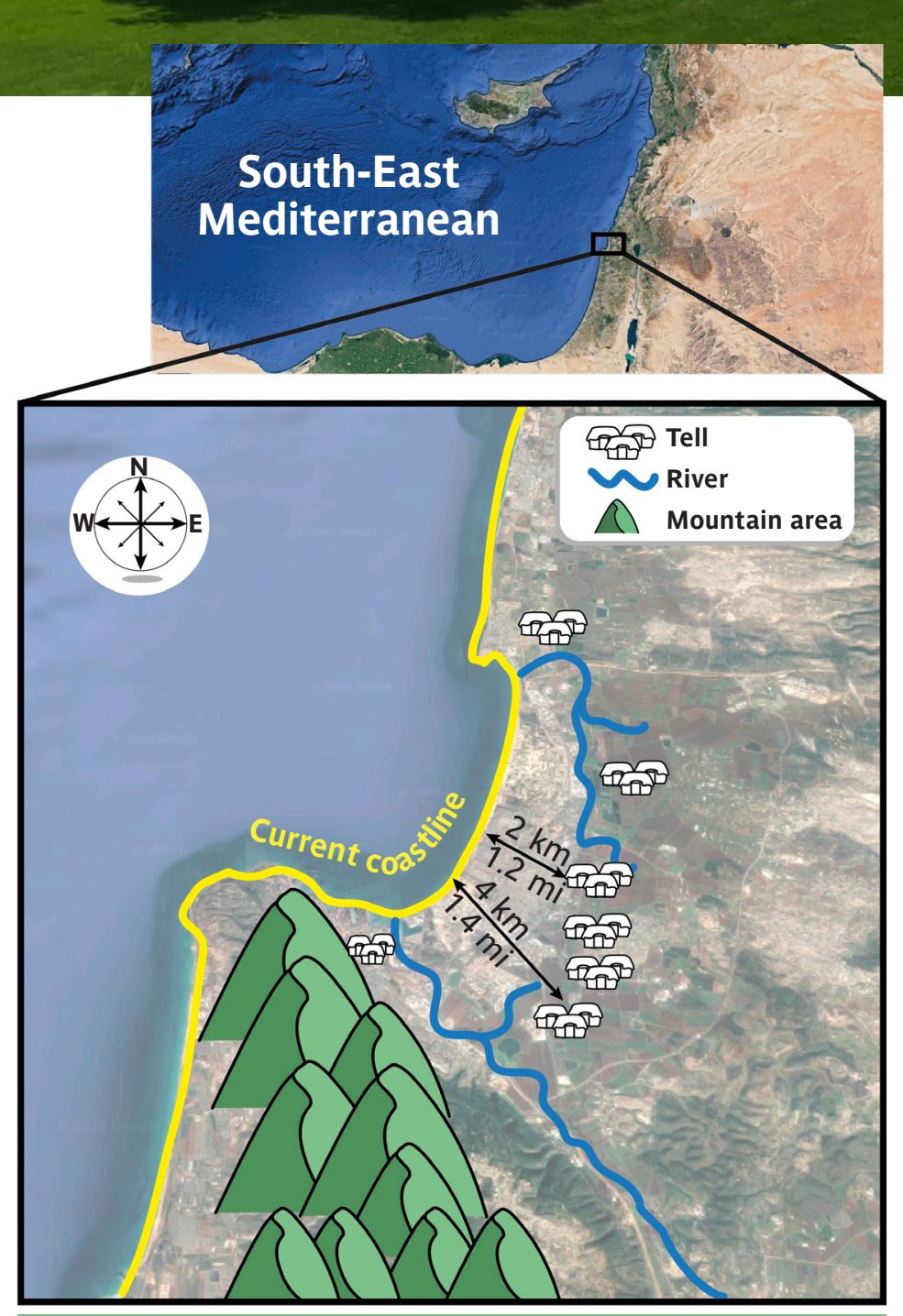

Figure 1: Marine and coastal area of Haifa Bay (Satellite images by Google Maps).

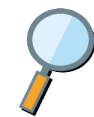

Observing the current coastal environment of Haifa Bay reveals a narrow, sandy coastline stretching almost linearly in the north-south direction. To the south, the coastal area is bordered by a mountainous area. The Mediterranean Sea stretches to the west and the land to the east and north. Two main rivers drain into the bay, thus delivering sediments to the bay. An array of Tells ("Tell" is the local term for an ancient settlement) stretches from south to north in a crescent-like shape. Tells are situated between $2-4 \mathrm{~km}$ (1-2.5 miles) away from the current coastline. 


\section{What can observations from a current}

\section{coastal environment tell us?}

If you visit different coasts around the world, you will notice many differences among coastal environments. Yet in general, there is a strip of sand between the sea and the land (geologists call this land "inland"). The width of that sand strip may differ from place to place, and features such as plants, shells, algae, sand dunes, and wetlands may be found in one place but not another due to different environmental conditions.
These represent the result of many processes in the coastal environment of the recent years. Monitoring and measuring the winds and ocean currents, plus the effect of storms, wave action, and tides, gives us an understanding of the processes that create these deposits along the coast. The location of the coastline is defined by where coastal sediments are found. Therefore, to find the location of the coastline in the past, we need to find such coastal sediments from the past, which are buried within the subsurface of different sediment layers.

To extract that infor-
mation from under-
ground, we drilled
cores along Haifa Bay in the
bay (west of the current
coastline), the beach, and
inland (east of the current
coastline). In cores where we
found coastal sand, we
sampled and measured the
age of the sand. We marked
the coastline 8000,6000 ,
and 4000 years ago on a
map. These results are very
clear - the coastline moved
from west to east during the
past 8000 years. This also
indicates that the sea level
rose from about 15 m (50 ft)
below today's sea level to its
current level.

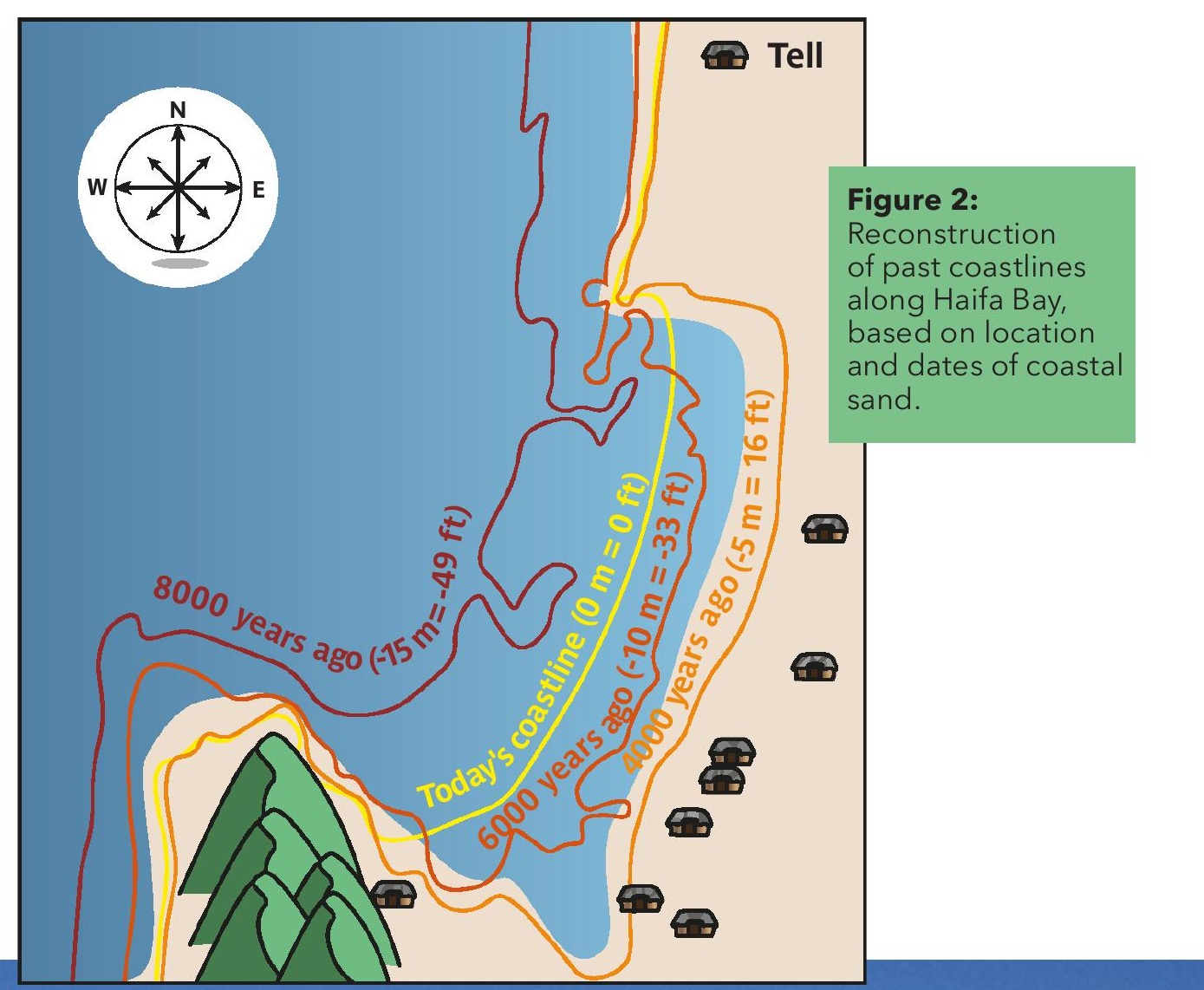

\section{Why does the coastline change with time?}

\begin{abstract}
The coastline changes because of changes in sea level with time. Sea-level changes differ from short timescales, as in hours for the tide, leading to a change of inches to feet (centimeters to meters). Over longer periods - thousands and millions of years - sea level can rise and fall tens to hundreds of feet or meters.
\end{abstract}

Because of the sea-level change, the location and the width of the coastline - the beach itself - is changing as sediments are removed from or added to the coast.

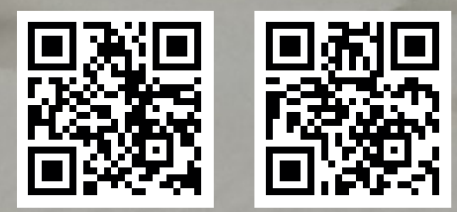




\section{How does the coastal environment change following sea-level rise?}

When we talk about a sea-level change, this refers to the height (or depth) of the water: a change in the vertical direction. However, the changes to the environment, such as the location of the coastline, are in the horizontal direction. When sea level rises, the coastline shifts inland, which affects the environments both onshore and offshore. As seen below, such a transition causes the coastline to migrate (move). This in turn leads to the build-up of water from river outlets, and a wetland is formed inland, behind the sand dunes.

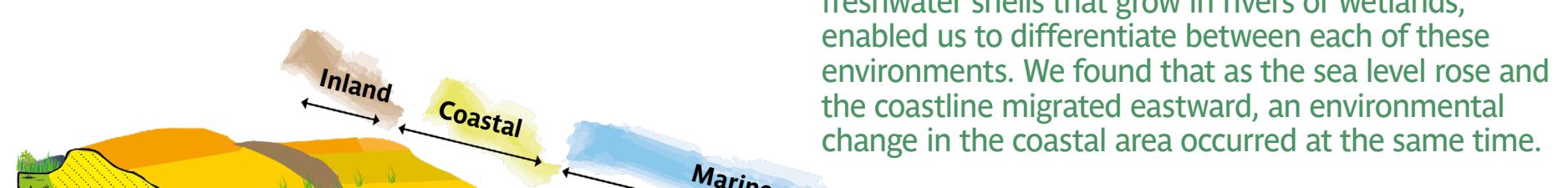
layers of sediments below the water in Haifa

Bay in two cores. The cores showed us that the coastline migrated eastward from around 7000 years ago over almost $3 \mathrm{~km}$ (2 miles) as a result of a global sea-level rise. However, this was not enough to determine the distance between the past coastline and some of the easternmost Tells. To do this, we had to examine the sediments, which showed us that through time, some locations that were marine became coastal and, later, even inland environments: special fossils found within the sediments, such as seashells or freshwater shells that grow in rivers or wetlands, enabled us to differentiate between each of these environments. We found that as the sea level rose and the coastline migrated eastward, an environmental change in the coastal area occurred at the same time.
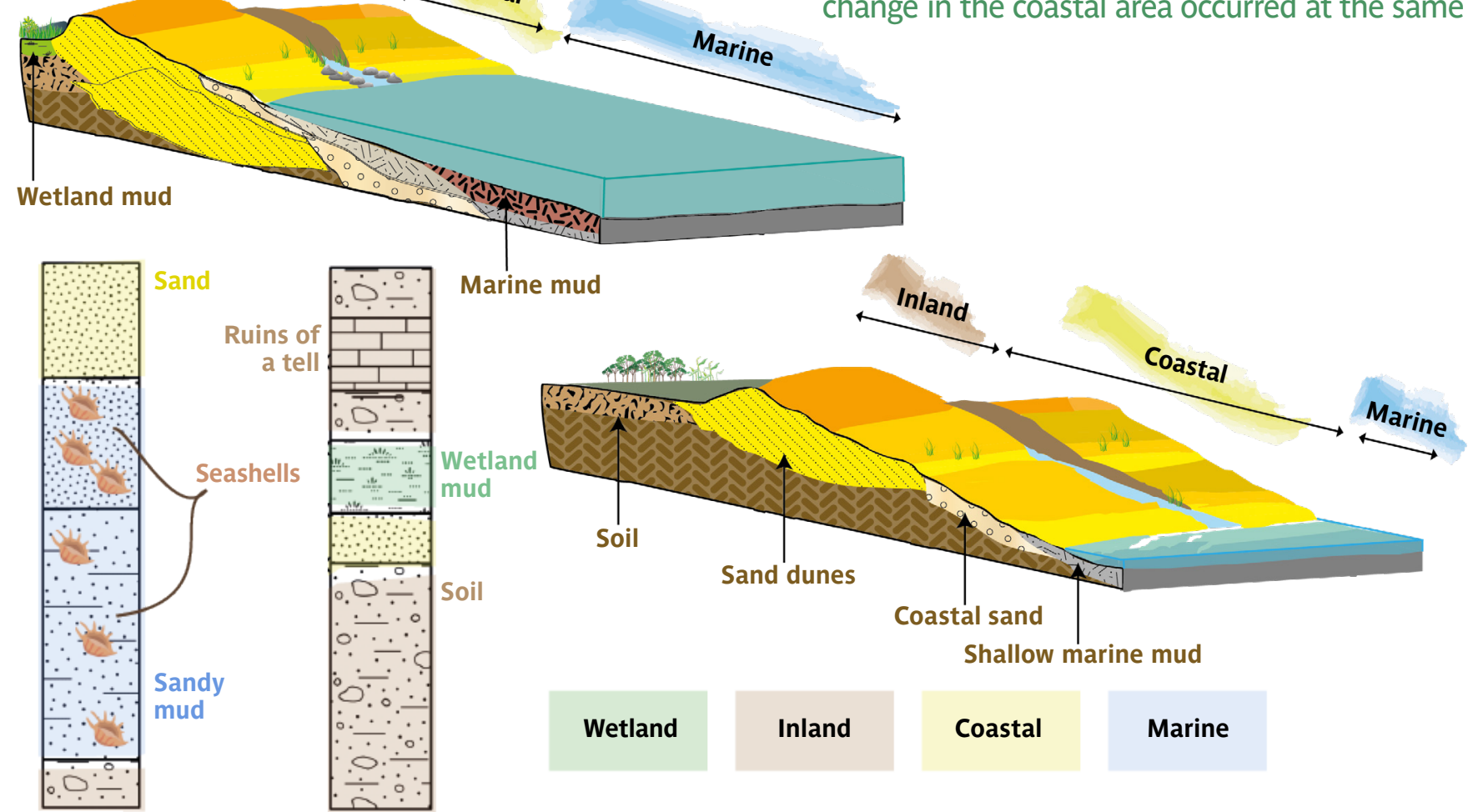

Wetland

Inland

Coastal

Marine

The environmental change in Haifa Bay was caused by a sea-level rise. Sand dunes formed along the coastline, blocking rivers from draining into the sea. The stagnant waters formed wetlands, which created a barrier, which made it more difficult to establish villages close to the sea in these locations.
Understanding the effects of sea-level rise on coastal settlements poses an important question: knowing that the sea level is currently rising, what will happen to our coastal cities in the future?

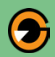

